\title{
A Review of m-Government Maturity Models
}

\author{
Dlamini Diteboho Refiloe, Mpekoa Noluntu \\ Central University of Technology \\ South Africa
}

\begin{abstract}
Mobile government is gaining significant attention worldwide. Mobile phone penetration offers government a number of several opportunities, including offering governments services to citizens through ambiguous devices. This phenomenon called m-Government is a strategy which implicates the use of all kinds of wireless and mobile technologies, applications and devices for improving service delivery to the parties involved in $m$-Government including citizens, businesses, employees and all government divisions. The study is based in South Africa, in preparation to be among the leading $m$ government intiative on the continent. The main aim of the study is to develop a mobile Government Maturity Model that can be used as an assessment tool to evaluate mobile services offered by government departments. This study examined the benefits offered by mobile government and also conducted an in-depth literature review on mobile government maturity models. Identified maturity models that have been developed by other researchers were translated, interpreted, compared and synthesized and a new mobile government maturity model is proposed. The new maturity model is contextualized for the Free State government in South Africa.
\end{abstract}

\section{Introduction}

Electronic-government (e-government) is one of the most rapidly evolving service domains in the contemporary information society. E-government refers to the use of Information and Communication Technologies (ICTs) for transforming the interactions among governments (G2G), governments and businesses (G2B), governments and employees (G2E) and governments to citizens (G2C) [1]. E-government is a concept of linking the society to the numerous units of government using automated and automatic way for getting all kinds of government services, in addition to the accomplishment of the government working itself depending on ICT to improve performance, reduce costs, the speed of delivery and effectiveness of implementation [4]. E-government contributes to the improvement of government services delivery to citizens, the facilitation of interactions with businesses and the empowerment of citizens through easy access to information and services [1].

Governments are making efforts to provide more services in alternative channels, which will increase variety and quality of services as well as citizen's participation in order to achieve full transformation of government services. The use of information and communication technologies assist governments to facilitate the daily administration and to implement a relocation of government services from government offices to locations that are closer to the citizens. However, there is a lack of satisfactory and appropriate infrastructures such as computers to be utilized, access to internet and access to funds. Developing economies like South Africa have it difficult to implement ICT projects like e-government in comparison to other developed countries.

The eruption of the use of wireless devices is forcing governments to shift from e-government to m-government, due to the remarkable commitment that mobile phones are attaining worldwide. Mgovernment can be considered as an extension to egovernment platforms. M-government is introduced to enhance and extend the reach of preferred services beyond the e-government delivery instrument, it involves the use of all kinds of mobile and wireless technologies, applications and devices to improve service delivery among businesses, citizens and government units [2]. M-Government is a new concept that is gradually gaining significant attention internationally [3].

Most countries have adopted m-Government, including South Africa (SA). To which extent are these $\mathrm{m}$-Government services have proliferated? No one knows, more especially in the Free State province in SA. This paper aims to investigate how to measure and assess the $\mathrm{m}$-Government services. The most well-known method to measure and assess m-Government services is to utilise a mobile government maturity model [4].

This study specifically analyzes well-known and accepted m-Government maturity models, which are mostly derived from e-Government maturity models. Then the study will synthesize the maturity models and present a contextualized model for the Free State province.

This paper comprises of five parts; Section 2 describes e-Government and m-Government in SA. Section 3 gives a brief overview of the methodology 
applied in this study. Section 4 presents the findings. Section 5 discusses the findings and presents a new m-government Maturity Model and Section 6 concludes the paper.

\section{Background Literature}

\subsection{E-Government in South Africa}

E-Government is a feasible use of ICT to empower improved information and service delivery as well as encourage participation in the decision making. E-Government implementations efforts around the globe began in the late 1990s [12]. The South African government is making use of ICTs to enhance work efficiency and improve service delivery to meet the needs of the public in a responsive and transparent approach [5]. Table 1 below is a summary of the general benefits for EGovernment.

Table 1. E-Government benefits [11]

\begin{tabular}{|c|c|c|c|}
\hline $\begin{array}{l}\text { Types of } \\
\text { Benefits }\end{array}$ & Government & Business & Citizens \\
\hline $\begin{array}{l}\text { Direct } \\
\text { Financial } \\
\text { Benefits }\end{array}$ & $\begin{array}{l}\text { Realising } \\
\text { Efficiency Savings: } \\
\text { To free resources } \\
\text { for public and } \\
\text { private innovation. }\end{array}$ & \multicolumn{2}{|c|}{$\begin{array}{l}\text { Reducing Burden: } \\
\text { Administrative } \\
\text { Impediments. }\end{array}$} \\
\hline $\begin{array}{l}\text { Direct Non- } \\
\text { financial } \\
\text { Benefit }\end{array}$ & \multicolumn{3}{|c|}{$\begin{array}{l}\text { Meeting Public Expectations: } \\
\text { Improving customer satisfaction and equity, } \\
\text { meeting security and privacy concerns, } \\
\text { transparency and choice. }\end{array}$} \\
\hline $\begin{array}{l}\text { Programme } \\
\text { Benefits } \\
\text { (Direct and } \\
\text { Indirect) }\end{array}$ & \multicolumn{3}{|c|}{$\begin{array}{l}\text { Improving Policy Effectiveness: } \\
\text { Achieving overall policy and programme } \\
\text { outcomes. }\end{array}$} \\
\hline $\begin{array}{l}\text { Good } \\
\text { Governance } \\
\text { Benefits } \\
\text { (Indirect for } \\
\text { Society) }\end{array}$ & \multicolumn{3}{|c|}{$\begin{array}{l}\text { Supporting Growth and Legitimacy: } \\
\text { Good governance contributes to a sound } \\
\text { business environment and democratic } \\
\text { legitimacy, promotion of the information } \\
\text { economy, supporting public sector reform and } \\
\text { creating business opportunities. }\end{array}$} \\
\hline
\end{tabular}

The benefits of E-Government can be grouped in categories of four namely: direct financial benefits, direct non-financial benefits, programme benefits and lastly good governance. This is the best practice from both developed and developing nation's intelligences on numerous benefits achieved by the government through using ICTs. However, with all the benefits mentioned, e-Government still has its own challenges and drawbacks. Millions of less privileged individuals are without access to internet through the use of a computer and still there is no realistic chance that they might access government services provided electronically [7].
Other e-Government challenges faced by the South African government include the following: high costs of internet, low levels of digital literacy among the society, lack of telecommunications infrastructure, low penetration broadband connectivity, geographical dispersion of the rural towns and villages, inadequate integration of poor citizens, privacy and security concerns, weak interagency information sharing, and inadequate empirical research to evaluate the impact of eGovernment on citizens livelihoods [8]. The government has realized that electronic service conduits via computers were moving slowly and not successful. The growing concern about the access inequality has led to consideration of new technologies as additional distribution channel for the services [9].

\subsection{Alteration from E-Government to $M$ - Government}

Changes regarding technology is making it difficult or impossible for any organization to conduct business without any assistant from ICT. Information Communication Technologies have comprehensively impacted the course of human development [29]. However, the drive of this paper is more focused on mobile technologies and communications, predominantly mobile phone technologies. Egovernment and m-Government are not two separate entities.

M-government is designed to build upon the already structured e-Government [10]. The penetration of mobile phone technologies in South Africa is elevating in such a way that the line between the mobile phone and desktop has blurred. This is due to the fact that mobile devices have become the computers in the pocket of every citizen to the point that it is no longer a case of digital divide but a case of digital difference. M-government is defined as the use of wireless technologies and mobile devices such as mobile phones, Personal Digital Assistant (PDA), smart phones, portable computers and Wireless Fidelity (Wi-Fi) enabled devices to deliver services anytime and anywhere [9], [11]. M-Government comprises of key delivery instruments that improves communication between mobile Government to Citizen (mG2C), mobile Government to Government (mG2G), as well as improving the operations among mobile Government to Business (mG2B) and mobile Government to Employee (mG2E). In the last decade mobile phone technology development has become a key strategy area for policy engagement in emerging economies, as this helps with the effective service delivery to the society.

The statistics in South Africa shows that the number of cellular subscriptions exceeds the number of population (105\%) [13]. Also, statistics show that the rate of growth of mobile phone use now exceeds 
that of fixed-line [14]. In addition, the results of a survey conducted indicated that $22.4 \%$ of citizens who wish to use e-Government services prefer to use the SMS or the mobile Internet, compared to $12.5 \%$ who prefer the internet channel via a computer. The adoption and penetration of mobile phones have been on the rise in South Africa with the increased cellular network coverage being a key driver to this growth. M-government is an important tool needed particularly in S.A. where half of its population resides in remote rural areas, informal settlements and townships and have a high risk of being by-passed by digital initiatives [15], [16].

Many government services can be made available on a $24 \times 7 \times 365$ basis at any place in the world covered by mobile networks, which today means almost everywhere [7], [12]. Mobile adoption in South Africa marks a distinctive opportunity to capitalize on mobilizing e-Government projects inevitably making government more accountable in a sense. Mobile phones have a unique advantage of being able to reach areas where the infrastructure necessary for internet service or wired phone service is not a viable option, and the rapidly increasing number of mobile phone users in developing countries reflects the demand for connectivity in these areas [2], [4].

Low cost of mobile phone technology versus internet technology drastically lowered the entry barriers for citizens in developing countries to be connected to government services [11]. Mobile devices are easier to use, learn and offers various benefits [3], [5], [10]. The most important government objectives of m-government implementation can be outlined as follows:

- Mobile Management: m-government provides facilities to improve management of internal activities of government organizations.

- Mobile services: transactions and mobile payments are as mobile informational services and a two-way communications service. Bank operations, purchases and sales activities can be facilitated by mobile tools.

- Mobile Democracy: one of the enormous potentials of mobile government is administration, hence mobile tools for mobile voting and democracy is implemented.

- Improve Mobile communication between government and citizens: vague information to the citizens will lead to them not making the right decisions.

Figure 1 shows the connection between diverse governments. M-Government is the subset of egovernment and the former is a supplement or extension of the later.

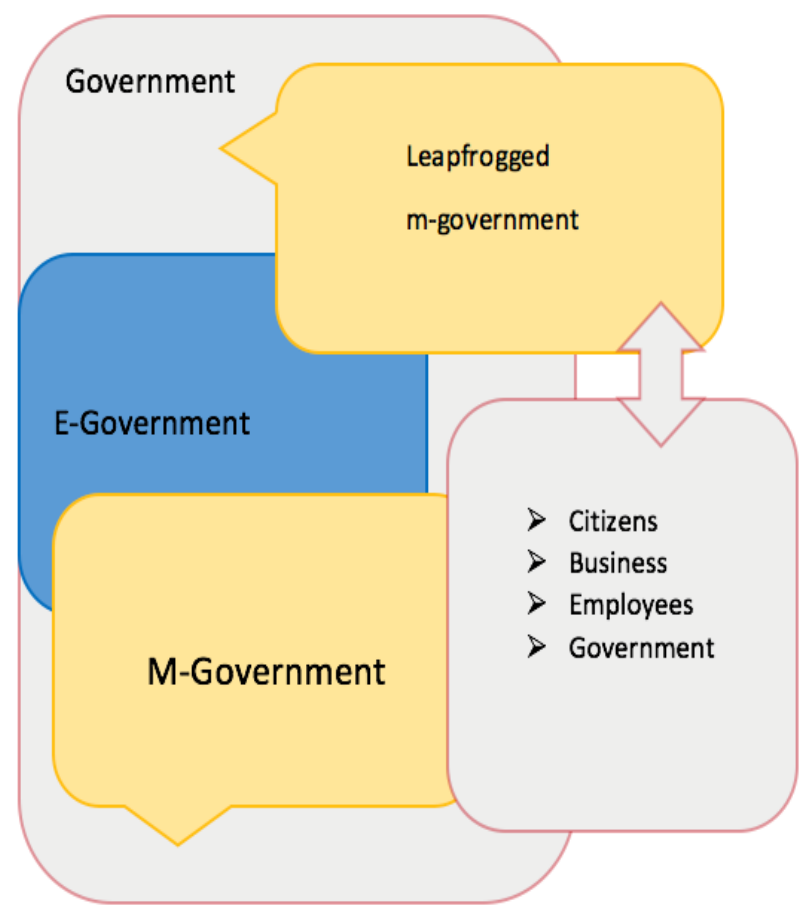

Figure 1. Synergies amongst m-Government stakeholders [29]

\subsection{Implementation of m-government in South Africa}

The citizens in South Africa find it overbearing to interact with the government for varies reasons. They constantly need the acquiescence from the government to do activities such as starting a business, paying up the taxes, obtaining a driver's license and many others required by the law.

Mukunza carried out a study that seeks to give a snapshot about the opportunities that m-government brings to the local government in South Africa, through using an urban municipality while using Polokwane municipality as a case study. Van Belle and Cupido conducted a study that investigated the opinions of South Africa's youth about interacting with government via their mobile phones. The study focused on local government participation, because the local arena is seen as a more immediate concern to respondents.

Mehlomakulu conducted research to determine the readiness of South African provincial governments. The study wanted to investigate the extent of readiness of the government and that of the underprivileged citizens for the introduction of $\mathrm{m}$ government within the Western Cape Provincial Government. The study further developed a reference model from the perspective of the province. Furthermore, Maleshoane conducted a study to develop a framework for the successful implementation of m-government using the Department of Home Affairs as the case study. 
Based on different studies conducted in South Africa by various researchers, examination shows that the majority of these studies are limited to the fact that they only looked at three segments of the government service delivery value mechanism namely: the Government-to-Citizen (G2C), Government-to-Employee (G2E), and Governmentto-Government (G2G). Various m-government systems have been implemented thus far. The South African Revenue Service (SARS) has adopted the use of SMS as a way to alert individuals and businesses about the status of their tax returns. The Department of Education has been using SMS to inform students about the availability of their matric examination results which indicates that the candidates' results are ready for collection at the writing center.

The Department of Education in the North-West Province has partnered with both Nokia and Mindset for the development and provision of educational content (which targeted mathematics competencies) for girl learners on their mobile phones. The Department of Home Affairs offers SMS notification to inform citizens about the status of their applications, this indicates the state of the application made and also notifies the applicants when the application is ready for collection. The Department of Health is also currently using mobile cellular technologies to send SMS medical alerts to tuberculosis and arthritis patients to remind them of their medication. All the systems provided are oneway communication by the government to the citizens; they are not usable by the citizens to communicate with the government.

This shows an indication of G2C. This means that majority of these implementation do not adhere to the fact that m-government is a matter of getting public sector IT systems to lean towards interoperability with citizens mobile devices and citizens, on the other hand, are able to communicate with the governments at any given time. Therefore, an m-government implementation such as those mentioned above which will take into consideration both G2C and C2G is inevitable in South Africa and throughout the developing world where mobile phones are used as the computer of the masses.

\subsection{Benefits and Challenges of $M-$ Government}

The societal problem that M-Government seeks to address in developing economies is that of amplifying government services delivery. Mgovernment offers the promise to improve internal performance, enhance efficiency and allow broadbased civil community in the information age. To achieve better performance services are ought to be modernized in such a way that those that cannot be offered through e-government are directed to $\mathrm{m}$ - government. Benefits comprises of [2], [3], [5], [7], [9], [14]:

- Convenience

- Convenience

- Less corruption

- Cost reductions

- Social improvements

- Greater convenience

- $\quad$ Easy and low cost

- Increased revenue growth

- Increased transparency

- Encourages interactive services

Mobile networks can be easily installed due to the simple architecture of mobile telephony. Very useful in developing countries, where infrastructure is an important issue [16], [27].

2.4.1. Challenges of M-Government. Although mgovernment presented many advantages, it also has some challenges. The challenges are examined below:

1. Authentication and validity of mobile: a rise of new technologies is caused to increase the importance of standard communication and policies in this area for connection between government agencies. Authentication should not be limited to a specific tool, this increases the risk of not allowing information to be accessed.

2. Lack of mobile government laws: some of the challenges in mobile payment is lack of laws and rules. When the government understand the role of mobile in presenting m-services, they will approve new laws and regulations for paying by mobile phone.

3. Security of mobile government services: security of communication is very challenging. Consequently, data protection, access of wireless tools to network, email security policies and applying security management tools and privacy in these areas are very important.

\section{5. m-Government Maturity Model}

Maturity Models (MMs) are designed to evaluate the development of the processes, people and objects/technology based on a set of principles [17]. M-government implementation is a continuing process and its development is conceptualized into stages (maturity levels) [4], [18]. A maturity model allows governments and researchers to measure and assess the performance of m-government 
implementations. Maturity Models assist governments to prevent from practicing ineffectively, evaluate if they are on the right track and direct governments on the next step of maturity in delivering m-government services where necessary [18], [19].

Maturity models play a crucial role in governments as they provide a roadmap that guides governments in their future plans, guideline on essential requirements in each maturity stage that enables citizens, businesses and employees to understand the government activities regarding to service delivery and can be used as communication tools to illustrate government potential capabilities [20]. The public will also get an opportunity to understand at which level are the government currently positioned and ways in which the government can improve to be able to move to the next level of maturity [4], [20]. The following section describes the methodology used.

\section{Methodology}

An in-depth literature study was conducted to have a fundamental understanding of the research problem. The creation of the stage maturity model is based on literature study, which made use of a qualitative meta-synthesis methodology to synthesize different m-Government maturity models. This process follows the steps in the meta-ethnography approach [17], [21]. Qualitative meta-synthesis is a technique for synthesizing the findings of qualitative research. The methods aim to explain the findings of a similar qualitative studies. The result is used as the basis for the design of the construct of $\mathrm{m}$-Government maturity model.

The primary sources of data were derived based on published articles, reviews, books and the government reports to gain essential data that assisted us to formulate a suitable mGovernment maturity model. After comprehensive and iterative literature search, several models of e-Government and $\mathrm{m}$ Government were identified.

Some similar models were developed by individual researchers and were confirmed in the academic literature. Others came from the reports and white papers from government, consulting firms and international organizations. The models have been published within last ten years, from 2005 to 2010 and are based on different perspectives.

\section{Findings}

Numerous studies were found relating to eGovernment maturity models but diminutive studies were found on m-Government maturity models. Only four studies were found, and they are presented in Figure 2. In m-Government development, there are two general phases to help develop the services [18],
[22]. The first phase is to provide what is already available in a computer-based application through mobile devices. The second phase is to provide those services and applications, which are only possible through wireless and mobile infrastructure [18], [23].

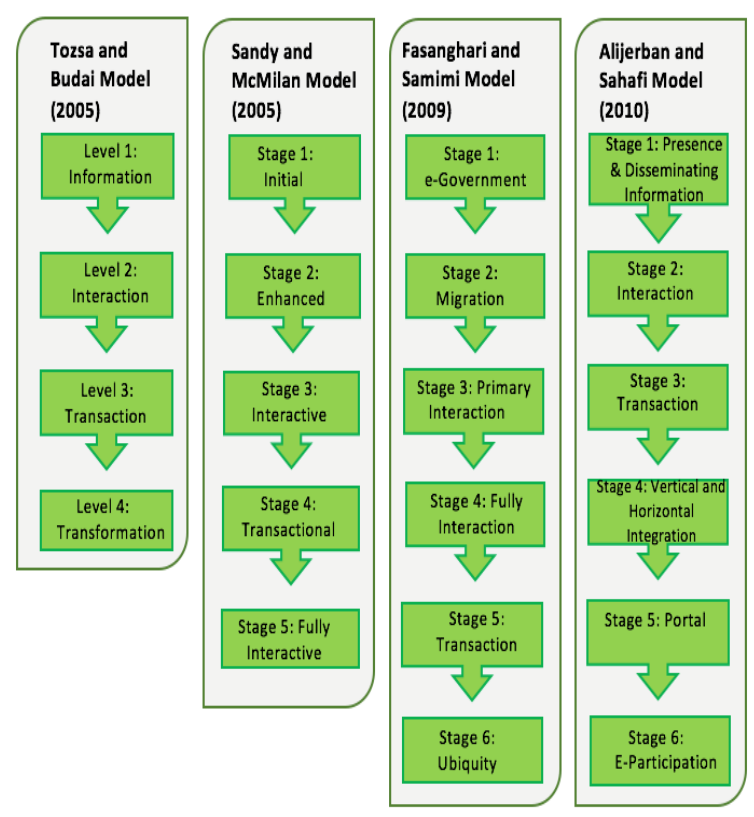

Figure 2. Mobile government maturity models

As aforementioned, there are limited studies on m-Government maturity models. Most of the researchers developed their maturity models based on a review of e-Government models [1], [8]. Models reviewed looked similar because all these models were constructed based on the development of eGovernment, m-government made use of mobile technologies to help the growth because of the rapid development it brings [7], [11].

This study has examined four m-Government maturity models that are available in scientific and practical fields. Tosza and Budai's [24] model made use of Gartner Group four-stage model for their mGovernment maturity model, through different phases of development it is intended to help progress mGovernment, the model consist of six levels of mGovernment maturity model which is discussed below:

Level 1: Information - this level projects communication through SMS. This level intends for the user to receive information and respond SMS over mobile network.

Level 2: Interactive - current level incorporates a collective transactional type which occurs with prompt responses via SMS or MMS technologies.

Level 3: Transactional - government provides services where different types of transactions are conducted through the use of mobile technologies over a mobile network. 
Level 4: Transformation - systems that have backend functionality are implemented by the government. The systems implemented are used to process administrative services through mobile technology.

Sandy and McMilan's [25] model compromises of five stages of functionality in electronic service delivery referring to both web and mobile. They propose a success factor model that presents the critical factors necessary for the success of any mgovernment project reviewed as follows:

Stage 1: Initial - this stage initially permits access to wireless services and responses that are noninteractive to the citizen.

Stage 2: Enhanced - the stage displays information in an updated routine, information such as policy changes and traffic conditions.

Stage 3: Interactive: at this stage communication among citizens and government service providers are provided. Features that enables the citizens to search for precise information based on the concern is made available. Citizens can conduct transactions with the government using wireless connections or mobile phones.

Stage 4: Transactional or mature interface - this offers a unique interaction for citizens through the use of mobile devices. Payment interaction that is not complex is provided for the citizen to conduct financial transaction with the government.

Stage 5: Fully interactive - provision is made for high security feature for mobile wireless transaction which can be made by the citizen for the government's services such as ordering, billing and payment. The services can be accessed from mobile device irrespective of the location of the citizen and they are accessible through a trusted secure authorization and identification.

Whereas, Fasanghari and Samimi [26] offer a sixstage m-Government model based on the general perspective of technology, security and infrastructure. They are presented underneath:

Stage 1: E-government - this stage is regarding electronic government where citizens can access government services with the infrastructures provided by e-government.

Stage 2: Migration: the stage offers accessibility to the information through using mobile devices. Implementation of a migration from e-government to $\mathrm{m}$-government is vital at this stage.

Stage 3: Primary interaction - citizens using their mobile devices can primarily interact with the government website. Ability to search specific information is granted on this stage.

Stage 4: Fully interaction - the citizens are able to interact and communicate with the government on a full scale through mobile devices. Compared to the previous stage, public service delivery is more convenient.

Stage 5: Transaction - based on the services that the government offers, citizens are provided with an opportunity to conduct transactions. Online interaction between citizens and government officials can now be put into effectiveness.

Stage 6: Ubiquity - government made services available in an ad-hoc method. Services such as weather forecast, information about disaster are made available without any request being made. Government delivers services straightaway.

On the other hand, Alijerban and Sahafi [21] propose a six-stage m-Government model based on general perspective with technological feasibility is reviewed:

Stage 1: Presence and disseminating information this stage allows mobile phones to access all websites and provide only basic services.

Stage 2: Interaction - offers the society a chance to download information through their mobile phones.

State 3: Transactional - society is given the opportunity to conduct financial transactions with the government. Government is responsible to safeguard personal details and privacy of the citizen.

Stage 4: Vertical and horizontal integration involves a machinery of communication which is integrated between institutions of governments are made available. The vertical and horizontal integration will not be possible to achieve through mobile technology if the country has not attained the integration of e-government implementation.

Stage 5: Portal and personalization - Conducting financial transactions and customizing how this transaction is conducted are made available to the citizen. Portal enables citizen to communicate with the government via a single interface, delivery to citizens is based on their individual needs and the services are allocated to various categories. Stage 6: Electronic participation - the government at this stage ensures that there is openness and accountability in the way that services are being delivered to the citizens. Services such as voting can be implemented in stage four, but it cannot be completely realized without transparency.

Our proposed maturity model insinuates that governments in developing countries should consider the use of social media to reach out to the citizens and accommodate even those in deep rural areas.

\section{Discussions}

Social media is one of the most growing trends in ICT more especially amongst the youth [16], [29]. Over the years social media is widely adopted by the 
public, it plays an important role in the implementing m-government. Social media refers to a set of online tools that are designed for and centered on social interaction, it accessed through applications or websites that allow operators to create, share instant content and real-time access on social network from their devices [10], [28]. Social media can be categorized into two different groups. First group is express social media which allows people to express themselves by sharing social with other people text messages, pictures, videos and music. This can be done on social platforms such as MySpace, Twitter, Facebook, Youtube, Flickr and Instagram. The second group is called collaborative social media, which empowers people to work together to achieve common goals through interactive and social processes. Google Docs and Wiki are great examples of this type of social media.

This technology can be undiscovered for the proliferation of $\mathrm{m}$-Government in the Free State. None of the other m-Government maturity models considers social media as an important phase in $\mathrm{m}$ Government proliferation [5], [14].

The domains and metaphors are essential and need to be explored as they assist when formulating an appropriate mobile government maturity model, the following are the metaphors and description for each phase of the mGovernment maturity model: Phase 1 (Movement): information is presented on the website and through the use of mobile devices. Phase 2 (Presenting): information can be published in the information space. Phase 3 (Mending): provides a two-way communication by improving the services between government and society at large. Phase 4 (Reforming): Allowing amendments for users to complete transactional activities. Phase 5 (Advance): offers a complex service that can be accessed at any time through social media. The following segment discusses the proposed m-Government maturity model [21], [26].

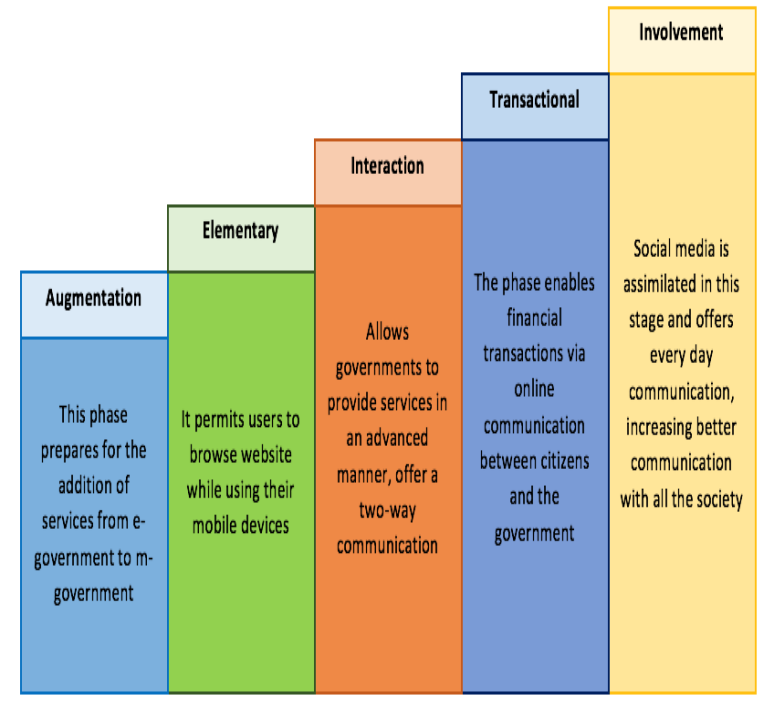

Figure 3. Proposed m-Government Maturity Model
In this study we propose a five-stage model by adapting and integrating critical factors that have been mentioned by other authors. Figure 3 below, presents the new model higher level. The addressed model contains the intention to use e-government services and e-Readiness.

First phase augmentation: given that mobile devices offers greater penetration it is vital to deliver government services via these ambiguous devices; this phase prepares for extension of services from eGovernment to m-Government. In this step with the use of mobile devices, access to government information is granted e.g. a user is able to do clinic appointment using a mobile phone.

Second phase elementary: this phase allows citizens to browse government web sites on their mobile devices. All sites should be designed in such a way that the citizens are able to access them via mobile devices, low sized software is compulsory. Services such as news, weather can be presented and can also be offered by Short Message Service (SMS) and email other than the web sites (Sending SMS to request available information for specific illnesses). Interactive responses are not yet available in this stage.

Third phase interaction: this phase allows governments to offer electronic services in a more advanced manner compared to previous phase. Interactions are made available for the citizens to network with government service providers, and a two-way communication is enabled. Users have the opportunity to download, fill in forms and submit them using their mobile device and wireless connection also an option of completing the form online and submitting immediately. For example, at this stage a user is able to get confirmation back and if need be can also cancel the appointment.

Fourth phase transactional: this phase provides financial interaction relations through online communication between the society and government for enforcement of the public services. Essentially, security at this stage is of utmost importance. In order to ensure that security is taken into consideration, information provided should remain confidential and user's privacy is also preserved safely. The most common examples here include the payment of government tax, traffic fines and others.

Fifth phase involvement: this phase provides greater convenience of mobile integration. Social media is incorporated in this phase and offers a $24 \times 7$ x 365 communication, increasing open partaking, anytime and anywhere access to accommodate all the citizens even those in rural areas. This will enable citizens to access information, ask questions, and get instant feedback using forums within web sites, Facebook and twitter. 


\section{Conclusion}

Nowadays, wireless technologies are becoming more and more popular in all ranges of network access, i.e. personal, local, metropolitan and wide. Such technologies have been widely acknowledged as complementary channels for two-way transactions between governments, citizens and businesses. As the mobile devices, networks and application evolve, mGovernment services will have to be provided through flexible and adjustable systems which can support different kinds of connections and terminals. In this paper, we have discussed e-Government and its challenges. We have also discussed an additional channel of providing government services through $\mathrm{m}-$ Government.

A careful review of the e-Government and mGovernment maturity models shows that a large portion of the published research was conducted in developed countries. In consequence, little is written about the m-Government deployment in developing countries, like South Africa. In order to develop the m-Government maturity model, a qualitative metasynthesis methodology was used to compare, interpret, translate and synthesize different existing maturity models.

Therefore, filling this gap in the literature is one of the main objectives for conducting this study in a country such as South Africa with various cultures and values. The outcome of this research revealed a new m-Government maturity model as part of improving public services delivery. Our next step involves conducting a survey which will explore mGovernment adoption barriers from the citizens' perspective.

\section{References}

[1] O. Al-Hujran, M.M. Al-Debei, A. Chatfield, \& M. Migdadi. "The imperative of influencing citizen attitude toward e-government adoption and use." Computers in Human Behavior 53 (2015): 189-203.

[2] Z. Wei, X. Gao, D. Jia, \& Y. Yang. "Research of mobile government based on multi-modal platform with unified engine." Intelligent Computing and Integrated Systems (ICISS), 2010 International Conference on. IEEE, 2010.

[3] J. Du Preez. Assessing the $\mathrm{m}$-Government readiness within the provincial government Western Cape. Diss. Stellenbosch: University of Stellenbosch, 2009.

[4] H. Abdelghaffar, and Y. Magdy. "The adoption of mobile government services in developing countries: The case of Egypt." International Journal of Information 2.4 (2012): 333-341.

[5] W. Amos. Exploring m-government readiness: the case of Vanuatu. Diss. Auckland University of Technology, 2011.

[6] N. Nkwe. "E-government: challenges and opportunities in Botswana." International journal of humanities and social science 2.17 (2012): 39-48.

[7] J.E. Mtingwi. "Mobile government readiness in Africa: the case of Malawi." (2012).
[8] L.F. Luna-Reyes, J. R. Gil-Garcia, and G. Romero. "Towards a multidimensional model for evaluating electronic government: Proposing a more comprehensive and integrative perspective." Government Information Quarterly 29.3 (2012): 324334.

[9] W. Palka, M. Jurisch, V. Schreiber, P. Wolf, \& H. Krcmar. "Mobile Government, Quo Vadis?Opportunities and Risks of Mobile E-Government Services." ICMB. 2013.

[10] C. Wang. "Antecedents and consequences of perceived value in Mobile Government continuance use: An empirical research in China." Computers in Human Behavior 34 (2014): 140-147.

[11] Z. Mitrovic, and N. Klaas. "The perceived benefits of introducing m-government services in the Western Cape." 2012 Conference. 2012.

[12] N.M. Yaghoubi, M. Pahlavani, and M. Bakhshimazde. "Effective Development of Mobile Government; Governance Approach." International Journal of Business and Development Studies 4.1 (2012): 87-100.

[13] S.A. Stats. "Statistics South Africa." URL: www. statssa. gov. za (2014).

[14] S. Mehlomakulu. The readiness for m-government in a South African provincial government. Diss. University of the Western Cape, 2014.

[15] M. Daniel. "Electronic government: A case for Papua New Guinea." Contemporary PNG Studies: DWU Research Journal 21 (2014): 154-166.

[16] M.R. Sultana, A.R. Ahlan, and M.D. Habibullah. "A comprehensive adoption model of m-government services among citizens in developing countries." Journal of Theoretical and Applied Information Technology 90.1 (2016): 49.

[17] G. Lee, and Y.H Kwak. "An open government maturity model for social media-based public engagement." Government Information Quarterly 29.4 (2012): 492-503.

[18] E. A. Maranny. "Stage Maturity Model of mGovernment (SMM m-Gov): Improving eGovernment performance by utilizing $\mathrm{m}$-Government features." (2011).

[19] G. Valdés, M. Solar, H. Astudillo, M. Iribarren. Concha, G., \& Visconti, M. "Conception, development and implementation of an e-Government maturity model in public agencies." Government Information Quarterly 28.2 (2011): 176-187.

[20] T. Mettler. "Maturity assessment models: a design science research approach." International Journal of Society Systems Science 3.1-2 (2011): 81-98.

[21] M. Alijerban and F. Saghafi. "M-government maturity model with technological approach." New Trends in Information Science and Service Science (NISS), 2010 4th International Conference on. IEEE, 2010.

[22] M. Bataineh, E. Abu-Shanab and A. Jdaitawi. "Mgovernment in Jordan: Today and the future." Proceedings of the 4th International Conference in Information Technology, Amman. 2009.

[23] T. Almarabeh, and A. Amer. "A general framework for e-government: definition maturity challenges, opportunities, and success." European Journal of Scientific Research 39.1 (2010): 29-42.

[24] I. Tozsa, and B. Budai. "M-Government, MWorkflow in Hungarian Research." Available: Brightontozsa1-1_2005 (2005): 04-29.

[25] G.A. Sandy, and S. McMillan. "A success factors model for M-government'." Euro mGov. Vol. 2005. 2005. 
[26] M. Fasanghari, and H. Samimi. "A novel framework for m-government implementation." Future Computer and Communication, 2009. ICFCC 2009. International Conference on. IEEE, 2009.

[27] O.S. Ogunleye, and J.P. Van Belle. "Exploring the success, failure and factors influencing $\mathrm{m}$ Government implementation in developing countries." IST-Africa Conference Proceedings, 2014. IEEE, 2014.

[28] J. A. Obar and S. S. Wildman. "Social Media Definition and the Governance Challenge-An Introduction to the Special Issue." Available at SSRN 2663153 (2015).

[29] Mukonza, R. M. (2013, October). m-government in South Africa's local government: a missed opportunity to enhance public participation?. In Proceedings of the 7th International Conference on Theory and Practice of Electronic Governance (pp. 374-375). ACM.

[30] A. M. Kaplan and M. Haenlein. "Users of the world, unite! The challenges and opportunities of Social Media." Business horizons 53.1 (2010): 59-68. 